\title{
The Effect of Clustering Technique towards Students' Achievement in Writing Paragraph of the Second Grade Students of Sman 1 Kuala Tungkal
}

\author{
Nurul Fitri* \\ Faculty of Teachers Training and Education, Universitas Batanghari, Jambi, Indonesia
}

*Corresponding Author: Nurul Fitri, Faculty of Teachers Training and Education, Universitas Batanghari, Jambi, Indonesia

\begin{abstract}
The purpose of the research is to investigate the effect of clustering technique towards students' achievement in writing paragraph of the second grade students of SMAN 1 Kuala Tungkal. In this research, students are expected to be able to write descriptive and recount paragraph by using clustering technique. The method used in this research is quasi experimental method. Since some factors that could influence, the result of the research is ignoring. The data are taken by administering progressive test and post-test. In this case, students of both groups are asked to write paragraph based on topic given by using clustering technique (for experimental group) and free writing (control group). The population of the research is all second graders of SMAN 1 Kuala Tungkal. For this research, simple random sampling was used as the sampling method. Moreover, there were some steps in analyzing the data: comparing mean scores of progressive test of both groups, comparing the value of t-calculated to the table. Based on the data analysis, the data of progressive test shows that the mean score of overall meetings which is caused by clustering technique was 9.97 while by free writing technique is 8.09. Furthermore, clustering technique has given differentt effect; it is 3.92 (based on t-test calculation). A single blue line can be drawn that clustering technique gives effect on students'writing.
\end{abstract}

Keywords: Clustering Effect, Students'Achievement, Writing Paragraph

\section{INTRODUCTION}

Writing is one of the English skills and belongs to productive skills. It means that writing is the output or product of receptive skills that students have mastered. They learn how to speak and write by reading or listening to others. Actually, writing skill is an ability to pass the process of transforming thought into written communication (Reimer: 2001). Furthermore, teaching writing is as important as finding out techniques of helping students to use their skills effectively on writing. Moreover, there are many techniques of writing, for example prompts, free writing, cluster, and outlining technique. Prompts technique is a technique which sets of questions helping students think about their topic from different angles. In this way, teachers provide some questions to help them writing. Free Writing technique is a technique where the students are asked to write quickly rather than focusing on correctness or sense, outlining technique is done by listing and organizing the ideas appeared in students' mind. This technique is organized in the order in which the information is presented from top down. Another technique is called clustering technique, (Rico. G.L:1983) develops clustering technique which involves writing down a word or phrase and engages it in free association. Each association is written down and connected to the original stimulus by an arrow or line. If association generates further associations, chains of associated words are produced. She also explains that cluster technique is done by starting to write the topic in a circle in the middle of a paper.

As other related ideas appear, these are written in smaller circles around the first circle. The related idea in each small circle may produce even more ideas. Moreover, Cluster helps students generate more ideas and during clustering, they freely add ideas if the ideas appear after another one.

Written language is a highly complex form of communication. It is both skill and a mean of self expression. The writing skill includes competence in writing, spelling, punctuation, capitalization and studying, making sound-letter correspondences knowing the alphabet and distinguishing one letter from another (Oktaviani:2010). That is why writing is not easy to be taught to the students and 
teachers often find difficulties to teach writing. As a result, students cannot compose or produce an effective writing result.

Related to this point, based on the observation at SMAN 1 Kuala Tungkal, the teachers never applied any techniques in teaching writing. They use the free writing technique in which students are asked to write a paragraph quickly rather than focusing on correctness or sense. As a result, the students think it is hard to write because sometimes they have no idea to write. They also find it is difficult to find and separate between main topic and subtopic to their paragraph. They don't know how to find, explain or arrange their idea to become the main or sub topic on their paragraph as well. Thus applying an appropriate technique is useful to help them to writing a composition in English. Based on this condition, this research is conducted in order to to help the students to improve their writing skill by applying a technique called clustering technique at the second grade students at SMAN 1 Kuala Tungkal.

\section{Clustering TechniQue}

Cluster technique is one of techniques done in prewriting stage. This technique was firstly developed by Dr. Gabrielle Rico in 1983 and adapted by Hendry in 1985 and 1986. Clustering involves writing down a word or phrase and engaging in free association. Each association is written down and connected to the original stimulus by an arrow or line. If associations generate further associations, chains of associated words are produced. It is assumed that the writer will be motivated to write further about the produced words and the connections made during the clustering exercise that will provide direction for the writing that follows.

For those who yearn to write but falter at the sight of a blank page, the unique, student-proven techniques in writing the Natural Way will help unlock natural writing style and storytelling abilities. Since 1973, Dr. Gabriele Rico has pioneered a dramatically different approach to writing that releases creative potential by tapping a rarely accessed part of the brain. Writing easily, meaningfully, and spontaneously is a simple matter of flowing with, rather than resisting, the mind's natural cooperative rhythms. By abolishing formal rules and quelling the painful inner critic, writing the Natural Way helps writers of all levels acquire the spontaneity and ease of uninhibited self-expression.

\subsection{Theory of Brain-Compatible Writing On Clustering Technique}

The theory of brain-compatible writing on clustering technique is taken from Gabriele Rico website. She explained that human beings are capable of processing the world in two distinct ways: Named Sign and Design mind, the Sign mind (left hemisphere) thinks linearly, parts-specifically, logically, one step at a time, while the Design mind (right hemisphere) thinks in whole patterns, drawing on images, emotional webs, sensory patterns, as in a memory that suddenly flashes into consciousness as a complex whole.

Although writing requires Sign mind sequencing, writing also requires global search strategies for what groups together, requiring the Design mind's non-linear jostling of emotions, memories, ideas. A too-hasty emphasis on Sign mind sequencing often shuts down the search strategies of our Design mind.

Clustering, developed by Gabriele Rico in her doctoral work, is largely a Design mind process. This non-linear brain-storming encourages playfulness, wide instead of narrow attention, and mental flexibility. By letting Design mind associations spill onto the page, clustering makes this non-linear search for patterns visible, manipulable and so, teachable and learnable - long before the sign mind steps in. Once both sides of the brain have a say in the writing process, the creative potential inherent in all of us is activated. The resulting writing flows quickly and easily.

\subsection{Clustering Technique Sample}

Here are the clustering technique samples which are taken from:

Step 1: Get a blank sheet of paper. On the top or centre of the paper, write a word or phrase that best represents your main subject or topic. Draw a circle around it.

Step 2: Around your first circle, write words that you associate with your main subject or topic. Write whatever comes to mind. For an example, in the middle of a blank sheet of paper, you might write the 
words How to Learn English. You'd then write whatever comes to mind that you associate with learning English - like practice English, do homework, go to school, use entertainment media and so on. You can also ask questions - like What must I do to learn English? These are your sub-topics.

Step 3: Circle your sub-topics and draw lines from the main subject to your sub-topics.

Step 4: Around each sub-topic, write words that you associate it. For an example, around the subtopic practice English, write whatever comes to mind that you associate with practicing English-like with my family, with my partners in class, everywhere I go, and so on.

Step 5: Circle those new words and connect them with the sub-topic. Branch out as much and as far as you can. Resist censoring yourself. Remember this is free association-there are no wrong answers. Some of the words your mind wanders to may surprise you, but keep writing. If you find yourself starting to force words, you can stop.

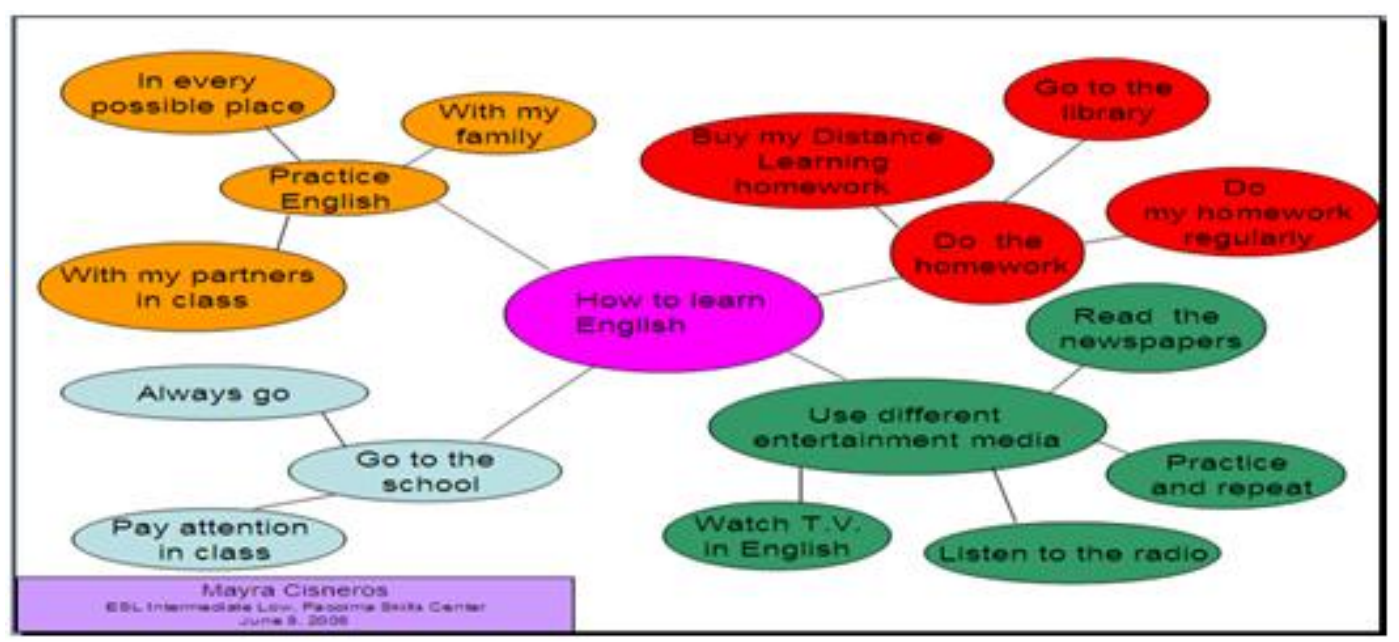

\subsection{The Procedure Of Clustering Technique}

There are several steps of clustering before writing (Meade, 2008):

- Write a nucleus word or phrase on a clean piece of paper. The nucleus word's purpose is to trigger associations. Emotionally charged words like "love, loss," or "envy" are extremely effective, as are prepositions: "around," "beyond," "over," and so forth.

- Circle the nucleus and let connections flow, writing down each new word or phrase that comes to mind, circling it and connecting it with a line to the word that sparked it. Attach to the nucleus each word that seems like an entirely new direction.

- Keep the hand moving all the time; do not stop. If getting stuck, keep circling words or thickening lines between them. You can even doodle, but do not stop moving your pen. As long as your hand is occupied, jotting thoughts and circling, your left brain-the "critic"-is occupied and thus is prevented from interfering with spontaneity and creativity.

- Start clustering for three minutes

- Continue adding to cluster if there is more to explore, reffering to cluster to stimulate thoughts as writing.

- Write piece without worrying about perfection. Get it all onto paper and later, go back to polish using the logical left-brain.

- Select the right branch to become the first paragraph, second and so on in accordance with the order provided by the teacher. For example, start from general case into specific or vice versa.

\section{RESEARCH DESIGN}

The method used in this research is quasi-experimental method. As Salkind (1991:232) point out that in quasi-experimental research, the hypothesize causes of the differences that may be observe between groups have already occurred. This design is selected since it is impossible to do randomization and 
assigned the subjects to several different groups. It is hard to do because the school where the research is conducted had its fixed system that could not be changed such as the number of classes, number of students, and time of study.

In this research, no equivalent control group design is used as the design of the research. The diagram of the design can be showed as follow:

\begin{tabular}{|l|l|l|l|}
\hline $\mathbf{G}_{1}$ & $\mathbf{O}_{1}$ & $\mathbf{X}_{1}$ & $\mathbf{O}_{2}$ \\
\hline $\mathbf{G}_{2}$ & $\mathbf{O}_{1}$ & $\mathbf{X}_{2}$ & $\mathbf{O}_{2}$ \\
\hline
\end{tabular}

(Adopted from Wiersma, 1986:143)

\begin{tabular}{llll}
$\mathbf{G}_{1}$ & : Experimental Group $\mathbf{X}_{\mathbf{1}}$ & \multicolumn{2}{c}{$:$ Treatment Clustering Technique } \\
$\mathbf{G}_{2}$ & : Control Group & $\mathbf{X}_{2}$ & : Treatment Free Writing Technique \\
$\mathbf{O}_{1}$ & : Pretest & $\mathbf{O}_{2}$ & : Posttest
\end{tabular}

On the diagram above, pretest $\left(\mathrm{O}_{1}\right)$ is given to both experimental and control group $\left(\mathrm{G}_{1}\right.$ and $\left.\mathrm{G}_{2}\right)$, then treatment is administrated to both groups (clustering technique for $\mathrm{X}_{1}$ and free writing technique for $\left.\mathrm{X}_{2}\right)$ for four meetings, and the last is giving posttest to both groups $\left(\mathrm{O}_{2}\right)$.

In this research, the objects of the research are two classes with the total students in each class are about 32 students. The researcher chooses XI IPA 1 as the control class and XI IPA 2 as the experimental class. Based on the data in the previous semester, the average score for these both of class is same. The score is not only from the English subject but also all the subject.

\section{FINDINGS}

\subsection{Pre-test Result of Experimental and Control Group}

Before giving the treatment, the first thing done is administering pre-test to both groups: experimental and control group. In both groups, the pre-test is administrated by asking the students to write maximally two paragraphs in recount based on the topic given; it is 'Funny Stories'. They should finish their writing in 45 minutes. Once as the topic is introduced, the students start to write their paragraph. Then, students' paragraphs are assessed based on writing analytic method.

The pretest result of experimental group shows that the mean score is 7.12 ; the highest score gained is 10. There are 3 students get it then the rest students get the score in the range of 3 to 9 . Meanwhile, the lowest score of pre-test result is 3. There are 3 students get the lowest score. Meanwhile in control group, the mean score is 7.75. Unlike the experimental, one student gets the highest score (14) and one student gets the lowest score (3). In addition, from the mean score, it shows that the students' effect in control group is not really different from experimental students before the treatment is given. It implies that both groups are equal so they are chose as the sample of the research.

\subsection{Progressive Test Result of Experimental and Control Group}

In experimental group, the mean score gain after five meetings are 9.97. While in control group, it is 1.88 different from the mean score of progressive test in experimental group. In the other words, the mean score of progressive test in control group is just 8.09. The complete data of progressive test result of both groups can be seen in table 1 .

Table1. The Progressive Test of Experimental and Control Group

\begin{tabular}{|c|c|c|}
\hline Meeting & Experimental Group & Control Group \\
\hline Pre Test & 7.12 & 7.75 \\
\hline Treatment 1 & 9.43 & 7.87 \\
\hline Treatment 2 & 10.12 & 8.03 \\
\hline Treatment 3 & 11.81 & 7.96 \\
\hline Post Test & 11.40 & 8.84 \\
\hline Average & 9.97 & 8.09 \\
\hline
\end{tabular}

In control group, the highest mean score of progressive test is gained at the fifth meeting (8.84) while the lowest is gained at the first meeting (7.75). Only at the fifth meeting, the result shows the better result and then on the next rest meetings, the mean score of progressive test has almost same mean scores as in first meeting (7.75) and it increases on the third meeting (8.03). The information about the difference of progressive test of both groups can be seen at the graphic below: 
The Effect of Clustering Technique towards Students' Achievement in Writing Paragraph of the Second Grade Students of Sman 1 Kuala Tungkal

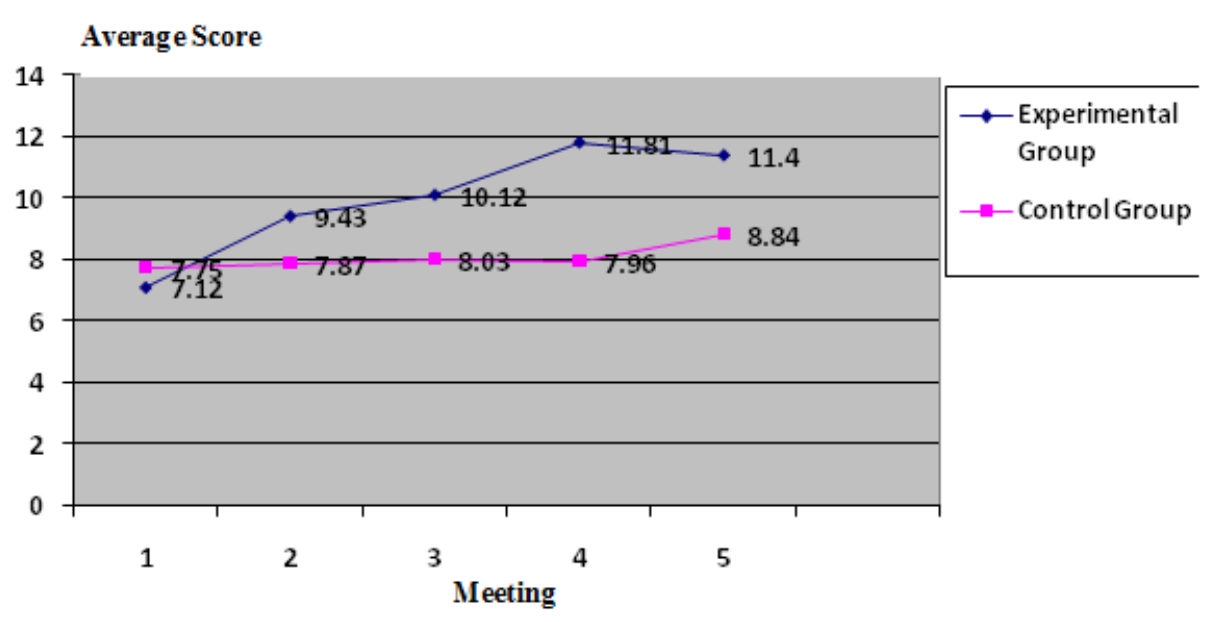

Result of Progressive Test

\section{DISCUSSIONS}

The students' paragraph is assessed based on analytic method. In this method, there are three major aspects evaluated in the system of fluency, grammar and vocabulary. Based on the result, however clustering has significant effect on students' achievement and it can be seen from the writing analytic method assessment.

Moreover, from the three evaluated aspects, clustering technique has given significant effect to all aspect. In other words, it helps a lot especially in the system of fluency or style and vocabulary. Moreover, the better achievement of students in experimental group which is gained to compare to those in control group happen for several reasons:

\subsection{Clustering technique enable the students to explore the ideas}

Clustering technique has several rules and they must be obeyed by the students. One of the rules is that the students should start writing the topic in the top or the center of a blank page and make a circle around it. Then, students write whatever comes to mind that associated with the main topic, it is called sub topic. After that, students make a circle again on the subtopic that has discovered and connected it with a line between the topics with the sub topics. Then, after the subtopic is made, students write again whatever comes to mind that associated with the sub topic (which is still related with the main topic), and make a circle around it, also connected it with a line for every idea that has discovered. Those idea will be arranged become a good paragraph.

Here is the example of student's clustering technique:

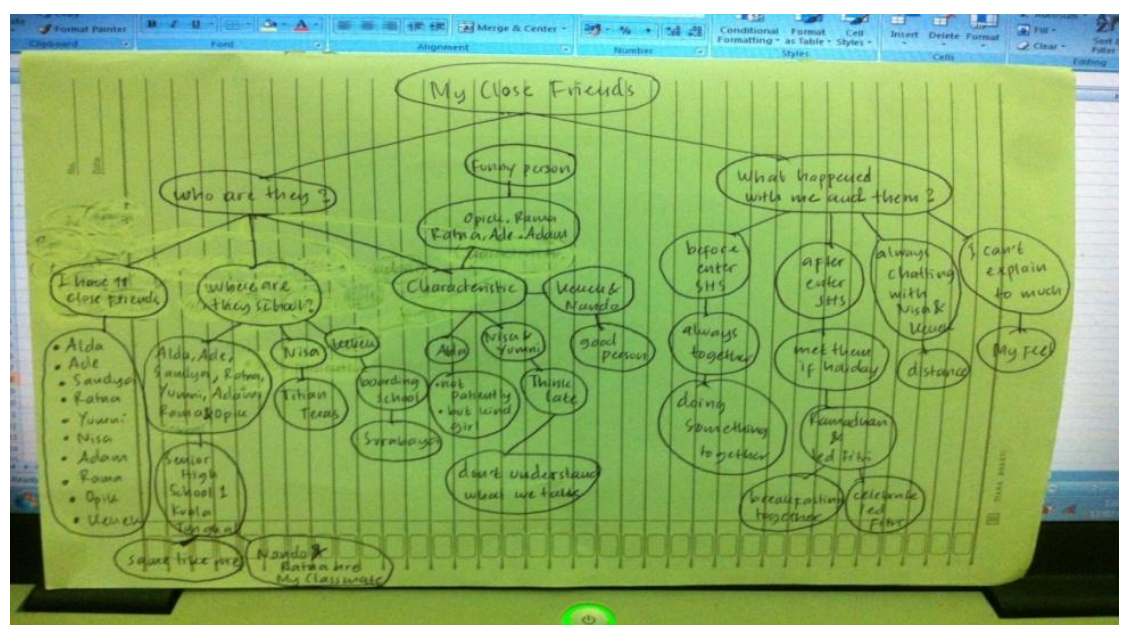

Source: Meeting 3, experimental group topic 'my close friend', and genre: descriptive

This data is taken from meeting 3 with the topic 'my close friend' and the genre is descriptive. From this example the student is able to explore their idea because of some factors. First, they write the topic at the top of blank page. It will enable them to generate their idea. In their clustering, it is seen that 
they will like to break down the topic into some idea. Those are about the description of her close friend 'My Close Friends' from generally to peculiarly, starts from who are they, where are they school, characteristic, what is happen with them, before entering senior high school, after entering senior high school, until what are their activity when holiday. From that description, she writes the story about 'My Close Friend' in a descriptive paragraph with quite following style, from simple until the complex information about her close friend fluently. In short, based on writing analytic method, the student's paragraph is assessed 15 point.

Regarding to the criteria, the example of students clustering and its paragraph shows that the students in experimental gain better achievement in the term of content. Based on the clustering they make, they can develop the topic and break it down to several ideas which are supported by relevant details (information). And it does not happen to the students in control group where the free writing technique is used. It does not help the students a lot in writing descriptive and recount paragraph. Here is the example of free writing make by the students in control group.

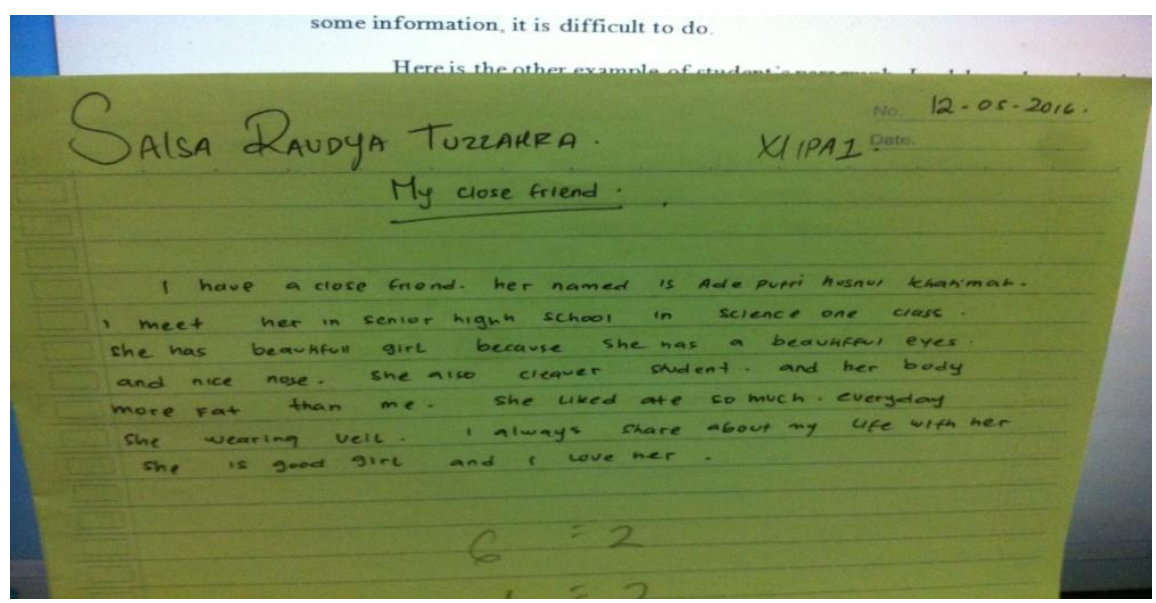

Source: Meeting 3, control group topic 'My Close Friend', genre: descriptive

From the free writing, it can be seen that the student in control group does not explore the ideas. She breaks the topic with only simple information; she starts from her friend's name, her simple information of her close friend physical description and her hobbies. In fact, the student can develop it more, like adding more idea in her general information for example about her address and her ages. Furthermore, the student also can add some idea of her close friend's hobbies.

The conditions above happen since free writing does not require 'flexible' way to explore the ideas unlike clustering technique, because the idea just written in the free way without any technique which is can give guidence for the student to help the student explore their idea. So, if the students want to add some information, it is difficult to do.

From the criteria, the data shows that the students in experimental group gain better achievement in the term of vocabulary. By clustering technique, they can add more relevant information and use variety of words and sentences. It makes their paragraph longer but relevant than those who are in control group. From some evidence above, in short, clustering has significant effect on students' achievement particularly, in the system of vocabulary.

\subsection{Clustering Technique as a Draft for Well Organized Paragraph}

From the data of progressive test and post-test, it shows that the students who are trained by clustering technique can organize their thought well. Based on writing analytic method, the assessment relates to the vocabulary aspect. On vocabulary aspect the paragraph are scored 5 if the paragraph use of wide range of vocabulary taught previously, scored 4 if use of new word acquired - use of appropriate synonyms, circumlocution, etc, scored 3 if attempt to use word acquired - fairly appropriate vocabulary on the whole but sometimes restricted - as two resort to use of synonym circumlocution etc. on a few occasion, scored 2 if restricted vocabulary - use of synonyms (but not always appropriate) - imprecise and vague effect meaning and scored 1 if Very restricted vocabulary inappropriate use of synonyms seriously hinders communication, the paragraph was hard to understand and could not enjoy reading. 
In practice, as the topic is introduced to the students in experimental group, they start to make clustering first before writing their paragraph. That is why the function of the clustering technique here is as guidelines so the students can write their paragraph in a well organize way. It can be concluded by analyzing and comparing between the pre-test result and progressive test result of experimental group.

In pre-test result, the students seem difficult to write the paragraph because they do not know how to start with. Then, they tend to write everything they think at that time without considering whether the information they include is relevant or not based on the topic. In other words, they put some irrelevant information then it interrupted the whole paragraph. Moreover, they also fail to write the paragraph in a good order. It seems they jump out from one idea to another idea so it would make the readers difficult to understand the whole paragraph. Here are the examples of students' writing which is less organize and has irrelevant idea:

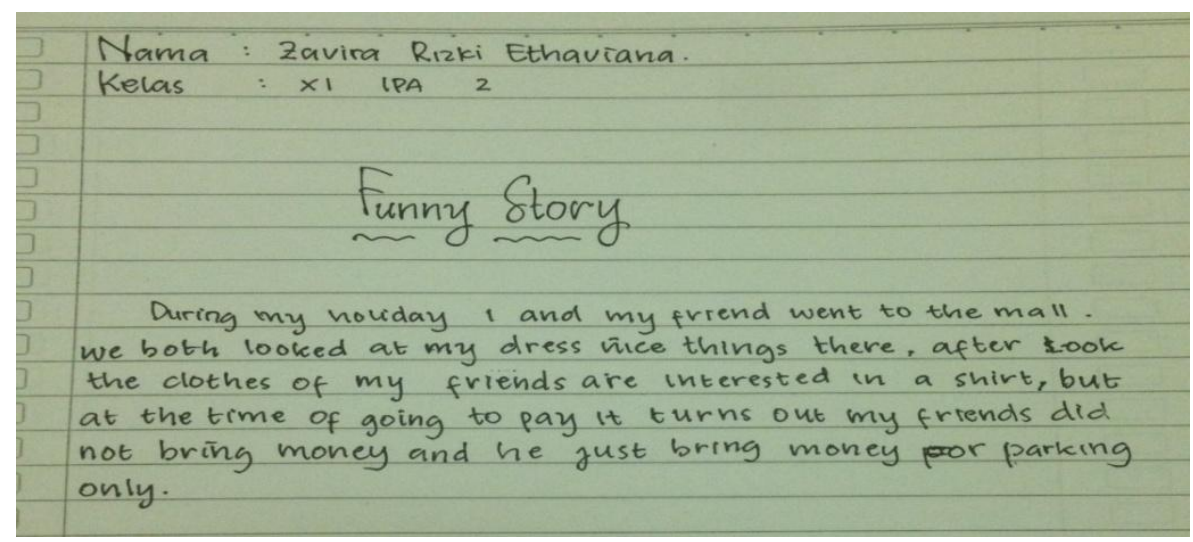

Example1. less organized paragraph

Source: Pre-test, experimental group, topic 'Funny Story', and genre: recount

From example 1 which is taken from pretest result of experimental group is a less organized paragraph. At the first sentence, student writes she is in the mall without any explaination about location of that mall. Next, she tells that she looks at a dress and wants to buy it, it is better for her if she can add more information about the object and separate her idea about the condition after realizing that her friend does not bring money in the second paragraph into another new paragraph. Thus it can be concluded that the student can not organize the idea well so the student's paragraph sometimes hard to understand by the readers.

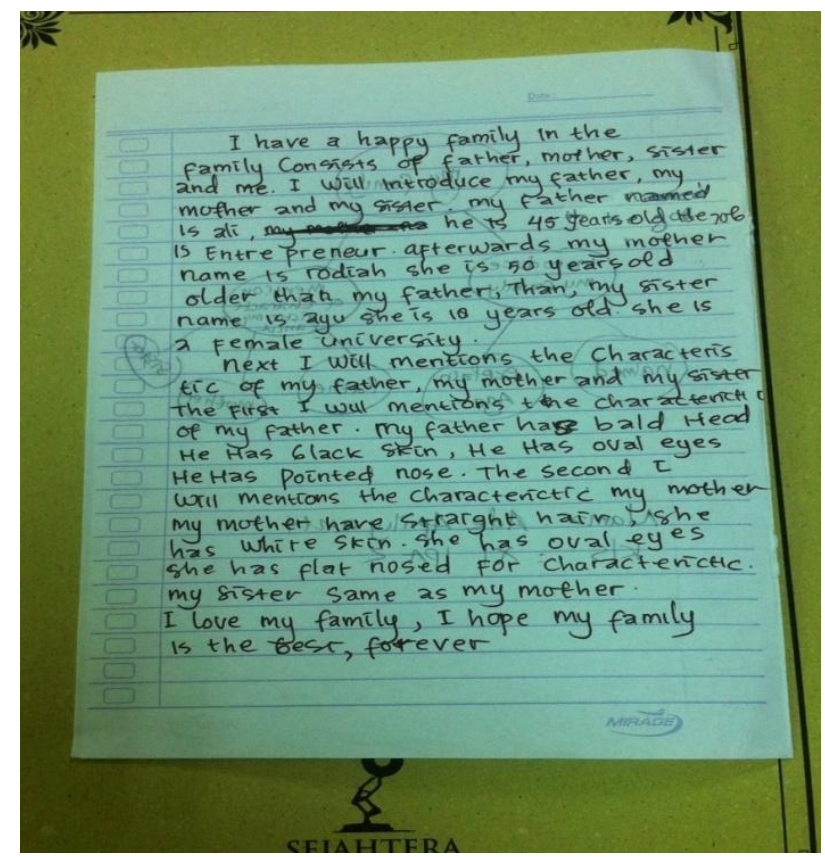

Source: Post-test, experimental group, topic 'My Family', and genre: descriptive 
Unlike experimental group where clustering technique is applied, the progressive test result shows that there is better achievement of students in the system of organization. Here, by using clustering as their draft, they 'have something to say' and they can add some information they need but still relevant to the topic. They also can make such 'sequence' for their paragraph so the readers can enjoy reading the paragraph. Here is the example of 'well organized paragraph':

From the example, it can be seen that the student can make well organized paragraph. By using clustering technique, the student can draft first what they are going to tell. Then, the student used the clustering technique as guideline to write the paragraph based on the topic. In paragraph one, the student focus on telling about the generally information about her family; name and ages. Next, in paragraph two, the student keeps the idea on the line telling about the characteristic of each member of her family. And in the end of paragraph she writes about her hope for her family. The student adds some information but they are still in the line so the information included is still relevant to the topic.

Thus, from the fact, it shows that clustering has given significant effect especially in the term of organization. They gain better achievement than those who are in control group.

\subsection{Clustering Technique Stimulates Creativity with Playfulness Activity}

As we know that writing requires certain technique to have a good writing. Thus, the students should be given one technique that makes them easier in writing. One of the techniques is clustering technique. As being explained before that clustering technique helps the students to exploring the idea quickly and spontaneously as a draft to write in a well organized paragraph. Then clustering technique requires students' creativity with playfulness process.

The students seem interesting in making clustering technique. They feel free to explore their mind spontaneously. The playfulness process when discover their ideas spontaneously has challenged their creativity to write as many ideas as they can that appear from the mind to the related subtopic that they make that also connected to the main topic that they get. The form of clustering also interesting, every idea, subtopic and main topic have to circle around it and it is connected each other by the line.

Based on observation during the research, though this research is conducted in five meetings, the students in experimental group are not bored to write the paragraph than the students in control group are bored because they are asked the same thing to write freely then write the paragraph based on the topic.

Here are the examples of clustering and free writing. See how they are different:

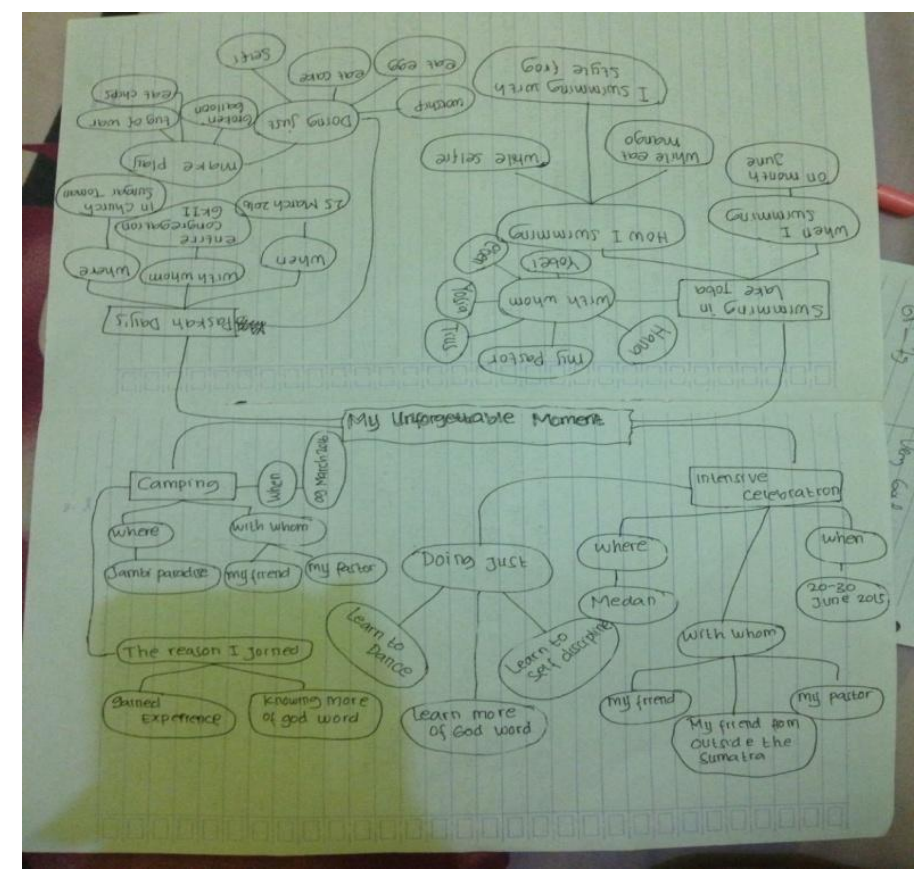

Example of Clustering Technique

Source: Meeting 3, topic 'my holiday, genre: recount 


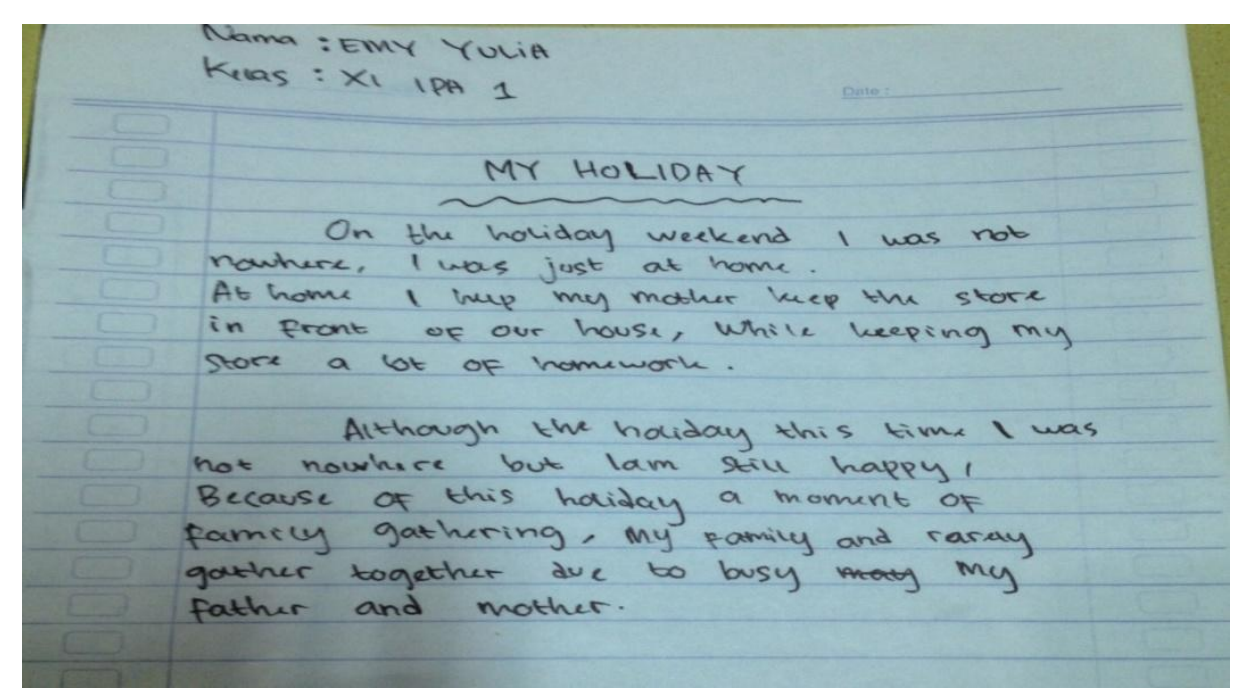

Example of Free Writing

Source: Meeting 3, topic 'My Holiday', genre: recount

Students in experimental made their clustering as many as possible. Started from the topic, they complete it by making an idea with circle around it that made spontaneously and quickly from their mind that related to the topic. For example, look at the example of clustering technique taken from meeting 5, the main topic of "Camping on Jambi Paradise" represented the topic of "My Unforgettable Moment'. The sentences have relation to the topic one to other. The student writes the paragraph with detail information. All of the sub topic and idea that has discovered by the student will be used in writing a well organized paragraph.

By all explanations above, it indicates that clustering technique can help the students to explore their idea. It functioned as a draft to make a well organize paragraph, and it can stimulate creativity by creates playfulness activity so the students are not easily getting bored. Unlike clustering, technique free writing is more 'awkward' technique, not enjoyable to do for the students in control group, the ideas may be written freely and not systematically. The last rule make the students in control group difficult to add some new information if they forget about the idea.

\section{CONCLusions}

Based on the result of the research, there is an effect difference on students' achievement on writing descriptive and recount paragraph between the eleven graders of SMA N 1 Kuala Tungkal who are taught by clustering and those who is taught by free writing. From the data of progressive test of both groups, the progressive test of experimental group shows that the mean score is 9.97. Meanwhile, the mean score of progressive test in control group is 8.09.

In addition, the mean score of post-test data in experimental is 11.40 and in control is 8.84 . Thus, the difference of mean score between both groups is 2.56. From the data, a single blue line can be shown that by clustering technique, students get better achievement of writing descriptive and recount.

In fact, there are three possible reasons: clustering technique enables the students to explore the idea, clustering technique functions as a draft for a well organized paragraph and clustering stimulated creativity with playfulness activity. In short, clustering technique possibly gives the significant effect on students' achievement on writing descriptive and recount paragraph.

\section{REFERENCES}

[1] S. Arikunto, "Dasar-Dasar Evaluasi Pendidikan," Jakarta. Bumi Aksara, 2007.

[2] Harmer, "The Study of Second Language Acquisition in the Asian Context," New York: The Word Publisher Company, 2002.

[3] Reimer, "Writing Process," Biringham: PACKT Publishing, 2001.

[4] G.L. Rico, "Writing The Natural Way," Retrieved from: http://www.amazon.com/reader/0874779618? encoding=UTF8\&page=28\#reader_0874779618, 1983.

[5] N.J. Salkind, "Exploring Research,” New York: Mac Millan Publishing Company, 1991. 
The Effect of Clustering Technique towards Students' Achievement in Writing Paragraph of the Second Grade Students of Sman 1 Kuala Tungkal

[6] Scott, “The Use of Mastering Writing Skill,” Monageng Monalagkwe: Botswana University, 1990.

[7] Sugiyono, "Memahami Penelitian Kuantitatif," Bandung: Alfabeta, 2001.

[8] W. Wiersma, "Research Methods in Education :An Introduction," Allyn and Bacon, 2009.

\section{AUTHOR'S BIOGRAPHY}

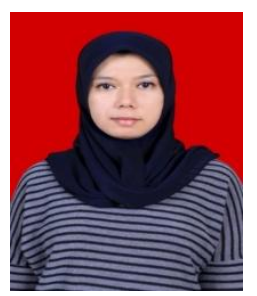

Nurul Fitri is a lecturer of linguistics in Faculty of Teachers Training and Education in Batanghari University, Jambi, Indonesia. She has been teaching for 8 years. She graduated from Master Program in Linguistics in Padjadjaran University. She currently teaches Introduction to Linguistics, Introduction to Literature, and General English.

Citation: Nurul Fitri. "The Effect of Clustering Technique towards Students' Achievement in Writing Paragraph of the Second Grade Students of Sman 1 Kuala Tungkal" International Journal of Humanities Social Sciences and Education (IJHSSE), vol 5, no. 9, 2018, pp. 128-137. doi: http://dx.doi.org/10.20431/2349-0381.0509018.

Copyright: (C) 2018 Authors. This is an open-access article distributed under the terms of the Creative Commons Attribution License, which permits unrestricted use, distribution, and reproduction in any medium, provided the original author and source are credited. 